\title{
To Study The Adverse Effect of Carbamazepine in A Tertiary Care Teaching Hospital of North East India.
}

\author{
Dr. Indrani Bhagawati ${ }^{1}$, Dr. Abdul Hakim ${ }^{2}$ \\ ${ }^{I}$ Associate Professor, Pharmacology, Fakhruddin Ali Ahmed Medical College and Hospital, India \\ ${ }^{2}$ Demonstrator, Pharmacology, Fakhruddin Ali Ahmed Medical College and Hospital, India
}

\begin{abstract}
To observe the specific pattern of adverse effect due to Carbamazepine (CBZ) and to determine the clinical relevance. A random once weekly data collection was done for a period of one year. Patients of all ages and both sexes were included in the study. Informed consent was obtained. Every patient was examined clinically and their side effects were detected. The data obtained was analyzed and presented with appropriate statistical methods. Unfortunately it was observed that Carbamazepine has wide spectrum of side effects. Severity of these adverse effects ranges from minimal impairment of the CNS to death from aplastic anaemia.
\end{abstract}

Keywords: Carbamazepine, antiepileptic, ADR, side effect, aplastic anaemia.

\section{Introduction}

Epilepsy is a collective term for a group of chronic seizures having in common sudden and transient episodes of disturbance of consciousness and/or a characteristic body movement, and sometimes autonomic hyperactivity [1]. Carbamazepine is a first line antiepileptic drug. It modifies maximal electroshock seizure as well as raises threshold to PTZ electroshock convulsion. It produces dose related neurotoxicity and many other side effect [2].

\section{Aims And Objectives}

The overall goal is to observe the specific pattern of adverse effect due to CBZ and to determine the clinical relevance. Seizures without causing untoward side effects preferably with a single medication and a dosing schedule that is easy for the patient to follow.

\section{Methodology}

This study was carried out in the Neurology department in a tertiary teaching hospital of North East India. This study was a prospective observational study. A random once weekly data collection was done for a period of one year. Patients of all ages and both sexes were included in the study. Informed consent was obtained verbally from the patients or legal guardian. Every patient was examined clinically and their side effects were detected. The data obtained was analyzed and presented with appropriate statistical methods.

\subsection{Selection of cases:}

A total of 152 cases were observed in the study period.

A total of 26 patients who presented with adverse drug reactions and were under the treatment of Carbamazepine were studied.

\subsection{Criteria for selection of cases:}

A diagnosis of the side effects of Carbamazepine was obtained after a detailed history of the present illness, past illness and the family history of each patient. The cases were then subjected to a thorough physical examination after which laboratory investigations were carried out. Besides a routine examination of a blood, other investigations were also done accordingly and where necessary, other special investigations were also carried out.

For purpose of study the following proforma was used.

Case no. __ Hospital No.___Name:____Age:__Sex;__Address:__Occcupation:__Date of examination:

H/O presentation of primary disease:

1.Duration of attacks; _ 2. Frequency of seizure:_ 3. Time of attack__ 4. Precipitating factors:__ 5. Presence or absence of a) premonition b) loss of consciousness c) type of seizure 6. Associated feature: 7. Post Ictal phenomenon 8. History- past, family, personal, menstrual and obstretric 9. Diagnosis 10. Antiepileptic drugs used- name, generic, trade, total daily dose-single/divided, route, other drugs 11. Details of ADR-symptoms, general examination, appearance, build. Nutrition, pallor, icterus, cyanosis, clubbing, skin, gum, tongue, JVP, lymph node, pulse, BP 
Systemic examination:

CNS: Higher examination:

Motor

Cranial nerves:

Reflexes

Sensory

Examination of cranium and spine

Sign of raised ICT

CVS:

RESP

GIT

\section{Investigation:}

I. Blood: TC___DLC___ESR___Hb___Sugar___Urea__Creatinine

Ii. X Ray: Pa View Chest, Ap \& Lat Skull, CT Scan/ Angiogram

Iii. Other Investigstion (Where Indicated)
CSF Lft
Rft
$\mathrm{Ct} \quad \mathrm{Bt}$

Iv. EEG

V. Drug Levels: After onset of ADR

The clinical part of the study compromised a total of 26 cases who had presented with adverse drug reactions to antiepileptic drugs in a tertiary care teaching hospital of North East India.

\section{Results}

Table I shows the age and sex distribution of the cases. Out of the 26 cases, 16 are male and 10 were female. The numbers of cases were maximum in the age group of 19-40 years.

Table 1: Age and sex distribution of cases

\begin{tabular}{|l|l|l|l|}
\hline \multicolumn{1}{|c|}{ Age } & Male & Female & Total \\
\hline $0-10$ & 1 & 1 & 2 \\
\hline $11-18$ & 4 & 2 & 6 \\
\hline $19-30$ & 4 & 2 & 6 \\
\hline $31-40$ & 3 & 2 & 5 \\
\hline $41-50$ & 2 & 2 & 4 \\
\hline $51-60$ & 1 & 1 & 2 \\
\hline $61-70$ & 1 & 0 & 1 \\
\hline & 16 & 10 & \\
\hline
\end{tabular}

Table 2: Doses of carbamazepine causing ADR in the patient

\begin{tabular}{|l|l|l|l|l|l|l|}
\hline Strength (mg) & 200 & 300 & 400 & 600 & 800 & Total \\
\hline Number of patient & 1 & 1 & 8 & 15 & 1 & 26 \\
\hline
\end{tabular}

Table 3: ADR related to CARBAMAZEPINE

\begin{tabular}{|c|c|c|c|c|c|c|c|}
\hline \multirow[t]{2}{*}{$\mathrm{ADR}$} & \multirow{2}{*}{$\begin{array}{l}\text { No of } \\
\text { patients }\end{array}$} & \multirow{2}{*}{$\begin{array}{l}\text { Mean time of } \\
\text { onset }\end{array}$} & \multicolumn{5}{|c|}{ DOSE [mg] } \\
\hline & & & 200 & 300 & 400 & 600 & 800 \\
\hline GI(nausea, vomiting) & 5 & 9 days & & 1 & 1 & 3 & \\
\hline \\
\hline 1.Hypersensitivity & 1 & 7 days & & & & 1 & \\
\hline reaction & 2 & 3 wks, 3 days & & & & 2 & \\
\hline $\begin{array}{l}\text { 2.Steven Johnson } \\
\text { syndrome } \\
\text { 3. Skin rash }\end{array}$ & 4 & 1 months & & & 2 & 2 & \\
\hline \multicolumn{8}{|l|}{$\mathrm{CNS}$} \\
\hline 1.Drowsiness & 7 & 3 wks & & & 2 & 5 & \\
\hline $\begin{array}{l}\text { 2.Momentary } \\
\text { disorientation, } \\
\text { amnesia, mental } \\
\text { slowing }\end{array}$ & 4 & 2 yrs & & & 1 & 2 & 1 \\
\hline 3.Vertigo & 1 & 7 days & & & 1 & & \\
\hline 4.Double vision & 1 & & & & 1 & & \\
\hline $\begin{array}{l}\text { Heamatological } \\
\text { (anaemia, purpura, } \\
\text { thrombocytopenia) }\end{array}$ & 1 & 1 year & 1 & & & & \\
\hline
\end{tabular}

Table 4: Side effect of CARBAMAZEPINE and the corresponding drug levels 


\begin{tabular}{|c|c|c|}
\hline Side effect & No. of cases & Mean drug level $(\mu \mathrm{g} / \mathrm{ml})$ \\
\hline A. GI(nausea , vomiting) & 5 & 8 \\
\hline \multirow{4}{*}{$\begin{array}{l}\text { B.Dermatological } \\
\text { 1.Hypersensitivity reaction } \\
\text { 2.Steven Johnson syndrome } \\
\text { 3. Skin rash }\end{array}$} & & \\
\hline & 1 & 6 \\
\hline & 2 & 4 \\
\hline & 4 & 6.5 \\
\hline \multicolumn{3}{|l|}{ C. CNS } \\
\hline 1. Drowsiness & 7 & 10.9 \\
\hline $\begin{array}{l}\text { 2.Momentary disorientation, amnesia, } \\
\text { mental slowing }\end{array}$ & 4 & 12 \\
\hline 3.Vertigo & 1 & 10 \\
\hline 4. Diplopia & 1 & 10 \\
\hline $\begin{array}{l}\text { D. Heamatological (anaemia, purpura, } \\
\text { thrombocytopenia)) }\end{array}$ & 1 & 7 \\
\hline
\end{tabular}

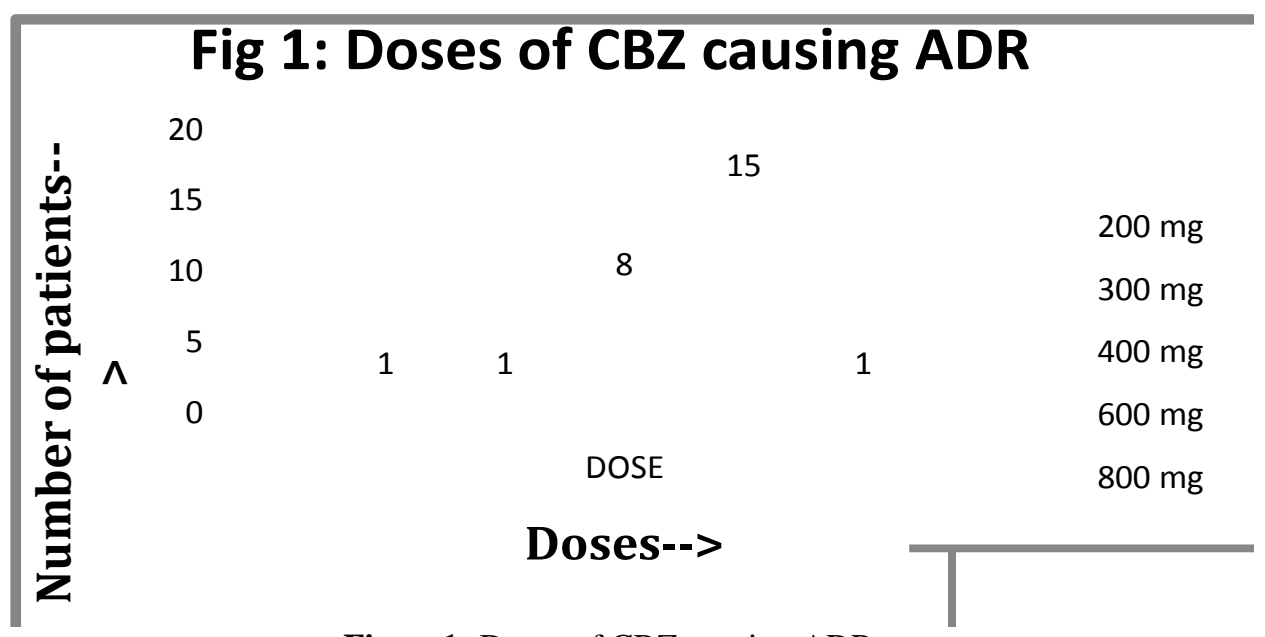

Figure1: Doses of CBZ causing ADR 


\section{Fig. 2: ADR RELATED TO \\ CARBAMAZEPINEowsiness, disorientation, a \\ mnesia, mental \\ slowing, vertigo, diplopia) \\ DERMATOLOGICAL(hypersensi \\ tivity, Steven Johnson \\ Syndrome, skin rash) \\ GIT \\ Manifestation(nausea, vomiti \\ ng)}

Figure2: ADR related to carbamazepine.

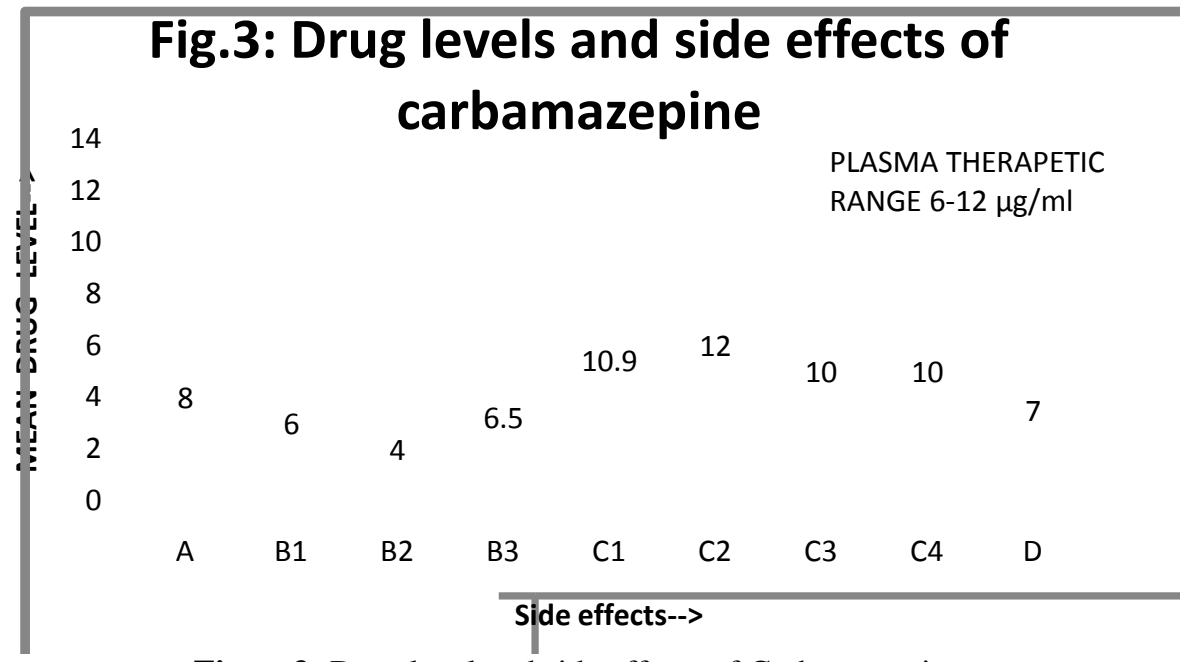

Figure3: Drug level and side effects of Carbamazepine
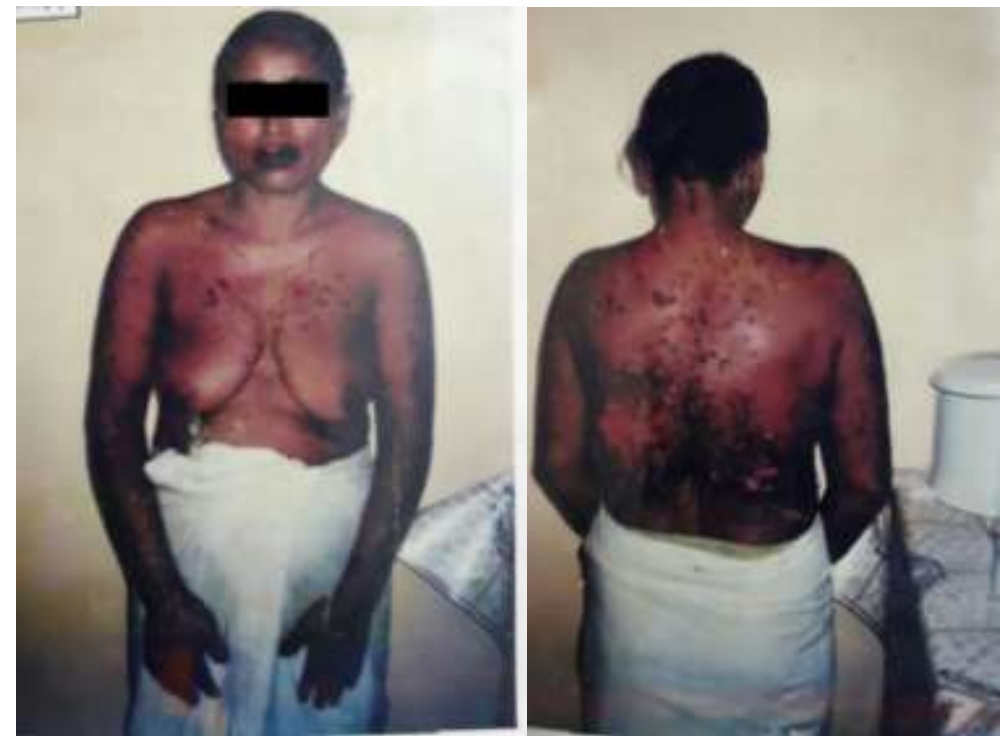

Figure 4: Steven Johnson Syndrome 

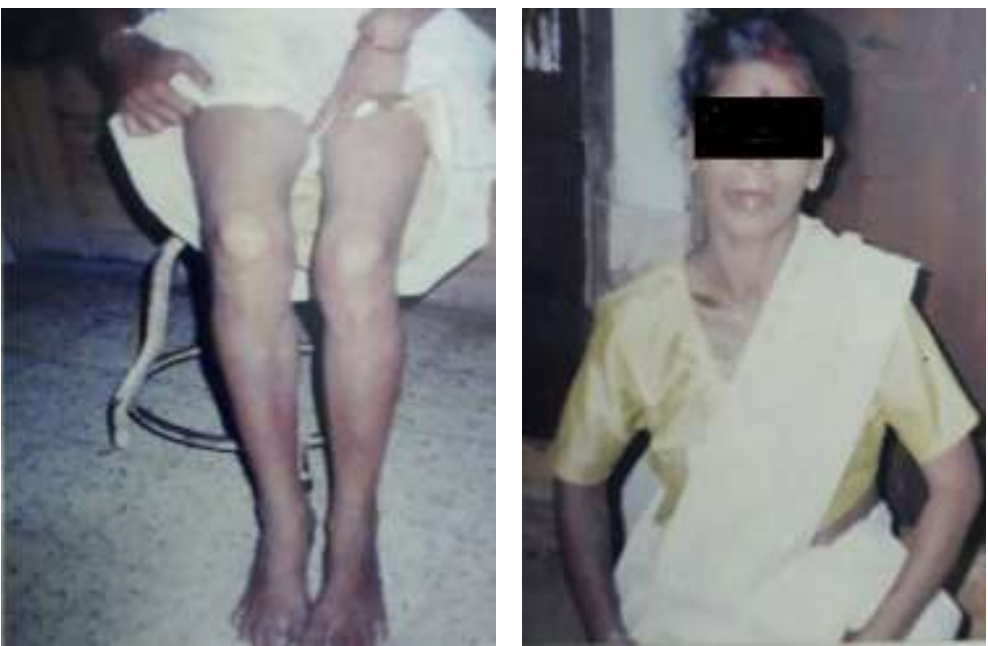

Figure 5: Allergic rashes due to Carbamazepine

\section{Discussion}

In this study adverse effect of CBZ was observed and correlated with serum level of the drug. A total of 26 cases who had presented in neurology department with adverse drug reaction to Carbamazepine were studied.

\subsection{Distribution of cases:}

Out of 26 cases, 16 were males and 10 females. This reflects a male female ratio of 3:2. A male preponderance in the sex incidence of epilepsy was reported as early as 1907 (Grower). Lenox and Lenox in 1960 reported a male female ratio of 2:1 over the age of 20 years. McHugh JC [3] reported male predominance, however Houser and Kurland (1975) [4] and Christensen J et al found an equal incidence in between sexes in localization-related epilepsy [5].

Since almost $30 \%$ epileptics are children, the paucity of children in this study probably because the paediatric patients usually report to the paediatric department in approximately 1 in 3000 exposures usually within first 2-8 weeks after initiation of therapy. Hypersensitivity reactions are common adverse drug reactions (ADRs) associated with antiepileptics [6]. One case of Steven' s syndrome was observed after 3 weeks of therapy which proved fatal.

\subsection{Adverse drug reactions related to Carbamazepine:}

26 cases adverse drug reactions due to Carbamazepine were observe in this study.

5 of the patients (19\%) become intolerant of the drug due to severe gastro intestinal manifestations like nausea $\&$ vomiting. 3 of these patients tolerated the drug after reducing the dose. The initial dose in these patients was $600 \mathrm{mg}$ daily which was probably high for the weight of the patients.

All allergic reactions were seen in 6 patients (23\%) receiving a dose of $400 \mathrm{mg}$ or $600 \mathrm{mg}$ per day after a mean period of one month of treatment. The reactions compromised of a typical macula popular eruptions. In one case exofoliative and eczematous reactions were seen. There was associated fever and lymphadenopathy in 2 of these cases. The incidence of allergic skin reactions with carbamazepine has been reported in upto $16.6 \%$ cases, (Chadwick et al ) [7], which agrees with the finding with this study. One case of Steven Johnson syndrome was observed in a patient after only 3 days of therapy. (Fig.4)

Central nervous system side effects are commonly seen with Carbamazepine. Seven of these patients (27\%) complained of drowsiness with doses of $600 \mathrm{mg}$ per day. This concurs with the observation of Salinsky et al [8] who observed sedation in $93 \%$ of the cases in their study. Trust et al (1996) reported an incidence of $20 \%$ which agrees with the findings in the study. Most of the patient improved after reducing the dose. Thus this are probably dose related side effect an observation made by Smith et al [9] and Pellock, J. M. [10] also.

Four patients on long term Carbamazepine therapy complained of mental slowing and momentary episodes of disorientation. One interesting case presenting with anaemia and with associated thrombocytopenia was also observed in this study. This was probably an allergic manifestations though the patient presented after one year of treatment. Interestingly all the side effects of Carbamazepine were seen at normal serum therapeutic level of the drug. The dose related side effects of Carbamazepine are reported to be dizziness, double vision, unsteadiness, nausea and vomiting (Chadwick) [11]. In this study the patients with drowsiness had a mean serum level of $10.9 \mu \mathrm{g} / \mathrm{ml}$, patient with diplopia, serum level of $10 \mu \mathrm{g} / \mathrm{ml}$ and gastrointestinal manifestations at the level of $8 \mu \mathrm{g} / \mathrm{ml}$. Thus CNS side effects were observed at higher normal levels. The chronic effects of the 
drug such as mental sluggishness, mild cognition impairment were seen at the upper limit of the therapeutic range $12 \mu \mathrm{g} / \mathrm{ml}$. The acute manifestations like skin rash, Steven Johnson syndrome and hypersensitivity reactions were observed at the level of $6.5 \mu \mathrm{g} / \mathrm{ml}, 4 \mu \mathrm{g} / \mathrm{ml}$ and $6 \mu \mathrm{g} / \mathrm{ml}$ respectively, which were within the therapeutic range. Hence with respect to dose related and chronic toxicity there is less correlation between serum level and the adverse reactions. Hence chronic toxic effects may be observed at high normal serum value of the drug. One reason for this could be the fact that some metabolites of Carbamazepine like the 10, 11 epoxide of Carbamazepine [12] may contribute to the therapeutic and toxic effect but are not routinely assayed. Moreover, only the free drug position is active in vivo, and this is not accurately measured. Salivary concentration of Carbamazepine correlated better with free drug concentration is expensive and not readily available.

When serum levels of Carbamazepine in the patients with adverse drug reactions were estimated, it was found that they were all in the normal therapeutic range of $4-12 \mu \mathrm{g} / \mathrm{ml}$. The allergic manifestations like skin rash and hypersensitivity syndrome were seen at the lower level of 4-6 $\mu \mathrm{g} / \mathrm{ml}$, while CNS related side effects like drowsiness and mental sluggishness were seen at the higher serum level of $10-13 \mu \mathrm{g} / \mathrm{ml}$.

\section{Conclusion}

Though this was limited study of adverse drug reactions of Carbamazepine, a wide range of possible side effects of this drug were highlighted. This study revealed the common pattern of adverse reactions seen on short and long term therapy with this antiepileptic drug. The side effects observed in this study were similar to those describe in other studies. Moreover this study showed the importance of monitoring of the levels of the drug in patients on chronic antiepileptic drug therapy. The major limitation of the study was lack of sophisticated laboratory facilities for more frequent drug level monitoring. Ideally drug levels after manifestations of toxic effects should have been compared with serum levels of the drug before appearance of these toxic manifestations.

Further study involving a larger number of cases of adverse drug reactions to Carbamazepine is necessary for a more meaningful and statistically relevant interpretation of this common problem facing epileptic patients who require long term drug therapy.

\section{References}

[1]. R. S. Satoskar, Pharmacology and Pharmacotherapeutics (Mumbai: Popular Prakashan,2007)

[2]. KD Tripathi, Essentials of Medical Pharmacology (New Delhi: Jaypee Brothers Medical Publishers Pvt. Ltd.,2014)

[3]. McHugh JC, Delanty N. Epidemiology and classification of epilepsy: gender comparisons. Int Rev Neurobiol; 83, 2008, 11- 26

[4]. Hauser, W. A. and Kurland, L. T., The Epidemiology of Epilepsy in Rochester, Minnesota, 1935 Through 1967. Epilepsia, 16(1): $1-66$

[5]. Christensen, J., Kjeldsen, M. J., Andersen, H., Friis, M. L. and Sidenius, P. (2005), Gender Differences in Epilepsy. Epilepsia, 46: 956- 960

[6]. Mehta M, Shah J, Khakhkhar T, Shah R, Hemavathi KG. Anticonvulsant hypersensitivity syndrome associated with carbamazepine administration: Case series. Journal of Pharmacology \& Pharmacotherapeutics; 5(1), 2014: 59-62.

[7]. Chadwick D, Shaw MD, Foy P, Rawlins MD, Turnbull DM. Serum anticonvulsant concentrations and the risk of drug induced skin eruptions. Journal of Neurology, Neurosurgery, and Psychiatry. 47(6),1984, 642-644

[8]. Salinsky, M. C., Oken, B. S. and Binder, L. M. (1996), Assessment of Drowsiness in Epilepsy Patients Receiving Chronic Antiepileptic Drug Therapy. Epilepsia, 37: 181- 187

[9]. Smith, Michael C.; Bleck, Thomas P., Convulsive Disorders: Toxicity of Anticonvulsants., Clinical Neuropharmacology, 14(2), 1991, 97-115

[10]. Pellock, J. M. (1987), Carbamazepine Side Effects in Children and Adults. Epilepsia, 28: S64- S70

[11]. Chadwick, D. (1994), Standard Approach to Antiepileptic Drug Treatment in the United Kingdom. Epilepsia, 35: S3- S10.

[12]. Theodore, W. H., Narang, P. K., Holmes, M. D., Reeves, P. and Nice, F. J. (1989), Carbamazepine and its epoxide: Relation of plasma levels to toxicity and seizure control. Ann Neurol., 25: 194- 196 